\title{
POTENCIAL PRODUTIVO DO MILHO EM FUNÇÃO DO TRATAMENTO DE SEMENTES COM MICRONUTRIENTES E INSETICIDAS
}

\author{
PRODUCTIVE POTENTIAL OF CORN IN THE FUNCTION OF SEED TREATMENT \\ WITH MICRONUTRIENTS AND INSECTICIDES
}

\section{Silvana OHSE${ }^{1}$; Jeferson Oles dos SANTOS ${ }^{2}$; Wagner Maciel MELLO²; Heverton Fernando $\mathrm{MELO}^{3}$}

\begin{abstract}
1- Docente do Departamento de Fitotecnia e Fitossanidade, Curso de Agronomia - Universidade Estadual de Ponta Grossa, Ponta Grossa/PR.

2- Engenheiros Agrônomos -Universidade Estadual de Ponta Grossa, Ponta Grossa-PR.

3- Pós-graduando do curso de Pós-Graduação em Agronomia da Universidade Estadual de Ponta Grossa, Ponta Grossa-PR.

Autor para correspondência: sohse@uepg.br
\end{abstract}

\section{RESUMO:}

A aplicação de inseticidas e micronutrientes visando maximizar a produtividade de culturas agrícolas via tratamento de sementes, vem sendo muito utilizada nas principais regiões produtoras do país, onde é adotado alto nível tecnológico no manejo de culturas. Neste cenário, desenvolveu-se um experimento na Fazenda Escola Capão da Onça, Ponta Grossa/PR, em delineamento blocos casualizados com objetivo de avaliar o efeito do tratamento de sementes com os micronutrientes zinco, boro e molibdênio (testemunha; ZnSO4.7H2O [na dose 16,5 g kg-1]; boro [MF Boro 10\% na dose 0,6 mL kg-1]; Molibdênio [MF Molibdênio 270 na dose 4,2 mL kg-1] e o produto StarG® [Formulado $4 \%$ de $\mathrm{Zn}+2 \%$ de Mo na dose $8 \mathrm{~mL} \mathrm{kg-1])} \mathrm{na} \mathrm{presença} \mathrm{e} \mathrm{ausência} \mathrm{de} \mathrm{inseticidas} \mathrm{(Cropstar}{ }^{\circledR}$ [imidacloprido+tiodicarbe] na dose $4 \mathrm{~mL} \mathrm{~kg}-1$ de sementes) sobre o desenvolvimento e potencial produtivo do híbrido de milho $\mathrm{CD} 321 \AA$, repetidos 4 vezes. As variáveis analisadas foram: número de folhas por planta; diâmetro de colmo e altura de planta aos 20, 50 e 80 dias após a emergência (DAE). No final do ciclo da cultura, avaliou-se a massa de 1000 grãos; diâmetro de espiga e de sabugo; comprimento de espiga; número de fileira de grãos por espiga; número de grãos por fileira e produtividade. Nas condições em que o experimento foi conduzido não houve interação entre os fatores para nenhuma das variáveis analisadas. A aplicação de inseticidas via sementes, apesar de ter reduzido o número de fileiras de grãos por espiga, proporcionou $13,6 \%$ de aumento na produtividade do híbrido de milho $\mathrm{CD} 321{ }^{\circledR}$. O tratamento de sementes com micronutrientes não influenciou o desenvolvimento e potencial produtivo do híbrido de milho CD321®.

Palavras-chave: Zea mays L., micronutrientes, tratamento de sementes, inseticidas, produtividade.

\section{ABSTRACT:}

The application of insecticides and micronutrients to maximize the productivity of agricultural crops through seed treatment has been widely used in the main producing regions of the country, where a high technological level is adopted in crop management. In this scenario, an experiment was carried out at the Capão da Onça School Farm, Ponta Grossa/PR, in a randomized complete block design with the objective of evaluating the effect of seed treatment with the zinc, boron and molybdenum micronutrients (control; $\mathrm{ZnSO}$.7. $2 \mathrm{O}$ [dose $16.5 \mathrm{~mL} \mathrm{kg-1]}$; boron [MF boron $10 \%$ at the dose $0.6 \mathrm{~mL} \mathrm{kg-1]}$; molybdenum [MF 
molybdenum 270 at the dose $4.2 \mathrm{~mL} \mathrm{kg-1]}$ and the StarG® product [Formulated $4 \%$ of $\mathrm{Zn}+$ $2 \%$ of $\mathrm{Mo}$ in the dose $8 \mathrm{~mL} \mathrm{kg-1])}$ in the presence and absence of insecticides (Cropstar ${ }^{\circledR}$ [imidacloprid + thiodicarb] at the $4 \mathrm{~mL} \mathrm{kg-1}$ dose of seeds) on the development and productive potential of the CD321® maize hybrid, repeated 4 times. The analyzed variables were: number of leaves per plant; stem diameter and plant height at 20, 50 and 80 days after emergence (DAE). At the end of the crop cycle, the mass of 1000 grains was evaluated; ear and cob diameter; length of spike; row number of grains per spike; number of grains per row and productivity. The application of insecticides via seeds, despite having reduced the number of rows of grain per spike, provided a $13.6 \%$ increase in yield of the CD321® corn hybrid. Seed treatment with micronutrients did not influence the development and productive potential of the CD321® corn hybrid.

Key words: Zea mays L., micronutrients, seed treatment, insecticides, productivity.

\section{INTRODUÇÃO}

A cultura do milho (Zea mays L.) desempenha papel fundamental no sistema de produção brasileiro e mundial. O elevado potencial produtivo, composição química e valor nutricional tornam este cereal um dos mais importantes, sendo consumido e comercializado mundialmente, sendo base da alimentação animal e humana, além de ser matéria prima para a produção de etanol (FANCELLI; DOURADO NETO, 2004).

O Brasil esteve até 2016, como terceiro maior produtor mundial de milho, atrás dos EUA e da China, todavia na última safra (2017/18) passou a segundo maior produtor e exportador mundial da cultura, com produtividade média na primeira safra $5.275 \mathrm{~kg}$ ha-1 e $4.721 \mathrm{~kg}$ ha-1 na segunda safra (CONAB, 2018), as quais são consideradas baixas se comparada à dos EUA (10.840,2 kg ha-1) (USDA, 2018), bem como, pelo potencial produtivo da cultura, o qual é superior a $16.000 \mathrm{~kg}$ ha-1 (COELHO et al., 2003).

O milho, nos seus estádios fenológicos iniciais de desenvolvimento, é bastante sensível a pragas que, quando da ocorrência podem causar danos em sementes, plântulas e plantas, entre a semeadura e pós-emergência, afetando a população de plantas. Por consequência, tornou-se prática comum tratar as sementes de milho com inseticidas, objetivando abrandar danos causados por pragas como percevejos das espécies Dichelops spp., Nezara viridula e Euschistus heros, que atacam o cartucho, danificando e podendo, muitas vezes, levar a planta à morte (GALLO, 2002). O tratamento de sementes com inseticidas também se faz importante no controle da lagarta do cartucho, Spodoptera frugiperda, praga extremamente danosa à cultura do milho, particularmente por poder atacar durante todo o ciclo da cultura, cortando a plântula na região do colo ou brocando a região do colo da planta jovem, todavia, em qualquer uma destas ocasiões a planta não conseguirá se desenvolver ou produzir de acordo com o esperado (QUINTELA et al., 2006). 
Por conseguinte, o tratamento de sementes com inseticidas é muito difundido e importante na cultura do milho, visando manter a população de plantas segura de pragas iniciais, consideradas as mais prejudiciais ao desenvolvimento e a produtividade da cultura (ALBUQUERQUE et al., 2006).

Somado à preocupação com o controle de pragas iniciais da cultura do milho, buscando-se elevar a produtividade, pode-se lançar mão da aplicação de micronutrientes, os quais são exportados da lavoura via grãos, sem a devida reposição. A reposição nutricional na cultura do milho se baseia na adubação de base com nitrogênio, fósforo e potássio, acrescida da adubação de cobertura com N, sendo o cálcio e o magnésio repostos somente quando da calagem e, para o $\mathrm{Mg}$ somente quando da utilização do calcário dolomítico. Não obstante, nos últimos 40 anos, muitas pesquisas foram desenvolvidas com o intuito de demonstrar a importância da reposição dos micronutrientes, tanto via solo, quanto via sementes e foliar (SANTOS; ESTEFANEL, 1986; SILVA, 1989; RIBEIRO; SOUZA, 1991; SANTOS; RIBEIRO, 1994; RIBEIRO; SOUZA, 1996; OHSE et al., 1999; MARCHEZAN et al., 2001; ÁVILA et al., 2006; ÁVILA et al., 2008; OHSE et al., 2013).

Perante o exposto, efeitos benéficos da aplicação de micronutrientes foram comprovados em várias culturas, entretanto, há muita divergência, denotando a necessidade de pesquisas regionais para melhor avaliar seus efeitos, principalmente pelo fato da maioria dos solos da região dos Campos Gerais, ser oriunda de rochas sedimentares, naturalmente pobres em micronutrientes. Além disso, são muitos os produtos comerciais contendo micronutrientes, ou seja, ampla composição química sendo utilizados, principalmente de forma curativa via aplicações foliares. Todavia, há carência de informações sobre a ação de micronutrientes específicos advindos de produtos puros por análise (p.a.), bem como de produtos comerciais aplicados via tratamento de sementes, bem como das interações quando da aplicação conjunta com inseticidas, principalmente para a cultura do milho. Neste contexto, o objetivo do trabalho foi avaliar o efeito do tratamento de sementes com inseticidas e produtos comerciais contendo micronutrientes (três fontes micronutrientes p.a. e uma mistura) sobre o desenvolvimento e o potencial produtivo da cultura do milho, híbrido CD $321 \AA$, para região de Ponta Grossa/PR.

\section{MATERIAL E MÉTODOS}

O experimento foi conduzido na "Fazenda Escola Capão da Onça" da Universidade Estadual de Ponta Grossa, situada à Rodovia PR-513, Ponta Grossa/PR, à latitude de 
2505'47" sul e 5003'11" a oeste, em uma área com altitude média de $1002 \mathrm{~m}$ em relação ao nível do mar. A região tem o clima classificado como Cfb subtropical úmido mesotérmico, conforme classificação de Köppen (PEEL et al., 2007) e, o solo da área é classificado como Cambissolo Háplico Distrófico de textura média (EMBRAPA, 2006).

A análise química do solo da área experimental foi realizada pelo Laboratório de Fertilidade do Solo da UEPG, na profundidade de 0 a $20 \mathrm{~cm}$ de profundidade resultando em: matéria orgânica (Walkley-Black)=43,1 g dm-3; 4,5 de pH em CaCl2; 24,2 mg dm-3 de P (Mehlich-1); 0,40 cmolc dm-3 de K trocável (Mehlich-1); 9,01 cmolc dm-3 de H+ Al (SMP); 0,7 cmolc dm-3 de Al trocável; 1,9 cmolc dm-3 de Ca trocável; 1,7 cmolc dm-3 de Mg trocável; CTC efetiva de 4,70 cmolc dm-3 e 42,6\% de saturação por bases (V). O teor de Zn foi mensurado no Laboratório de Análise de Solo da Fundação ABC, cujos resultados foram 2,9 mg dm-3.

O híbrido de milho utilizado foi o simples da Coodetec CD321®, de ciclo precoce, recomendado para a safra normal na região Sul do Brasil. Este material tem como características desenvolvimento inicial rápido, sendo tolerante ao tombamento e ferrugens, é um material de duplo propósito tanto para a produção de grãos como para a produção de silagem, o que se deve ao seu elevado valor nutricional. A população recomendada para nossa região gira entre 60.000 e 70.000 plantas por hectare, atingindo altura entre 2,10 e 2,5 m e, inserção de espiga de 1,10 a 1,40 m.

Para implantação da área experimental, procedeu-se primeiramente a dessecação da área, realizada no dia 07 de novembro de 2008, utilizando-se para isso o herbicida sistêmico, não seletivo Trop®, na dose de 2,5 L de p.c. ha-1. O delineamento estatístico utilizado foi o de blocos casualizados (DBC), com 4 repetições. O fator principal foi tratamento de sementes com diferentes micronutrientes (testemunha; zinco [ZnSO4.7H2O na dose $16,5 \mathrm{~g} \mathrm{~kg}-1$ de sementes]; boro [Cloreto de Boro $10 \%$ na dose 0,6 mL kg-1 de sementes]; molibdênio [Cloreto de Molibdênio $16 \%$ na dose 4,2 mL kg-1 de sementes] e o produto $\mathrm{Zn}+$ Mo [produto StarG® [4\% de $\mathrm{Zn}+2 \%$ de Mo na dose $8 \mathrm{~mL} \mathrm{kg-1}$ de sementes]) e, o fator secundário, o tratamento de sementes com inseticidas (Cropstar®) [imidacloprido+tiodicarbe] na dose $4 \mathrm{~mL} \mathrm{kg-1} \mathrm{de} \mathrm{sementes} \mathrm{e,} \mathrm{a} \mathrm{testemunha),} \mathrm{totalizando} 10$ tratamentos arranjados em fatorial 5x2, perfazendo 40 unidades experimentais distribuídas ao acaso dentro dos blocos.

Foram utilizadas $250 \mathrm{~g}$ de sementes para cada tratamento, sobre as quais se adicionou as doses. As doses foram ajustadas a quantidade de sementes tratadas, pesadas, diluída em água destilada, completando-se sempre o volume para $5 \mathrm{~mL}$. Após 
adição da solução sobre as $250 \mathrm{~g}$ de sementes, agitou-se manualmente até completa homogeneidade para garantir que houvesse maior uniformidade na distribuição dos produtos sobre as sementes. Procedimento realizado um dia de antes da semeadura.

A demarcação da área foi realizada no dia 16 de novembro de 2008 bem como o sorteio dos tratamentos dentro de cada bloco. No dia 18 de novembro a área foi riscada e adubada com semeadora, utilizando-se $300 \mathrm{~kg}$ ha-1 da fórmula 10-20-20 que foi igualmente distribuído na área. A semeadura foi realizada manualmente, com o auxílio de bengalas no mesmo dia da marcação, período vespertino, utilizando-se 5,2 sementes por metro linear compondo uma população de 65.000 plantas ha-1. As parcelas experimentais foram constituídas de 5 linhas de semeadura espaçadas em 0,80 m, sendo que cada linha conteve $5 \mathrm{~m}$ de comprimento, totalizando uma área de $20 \mathrm{~m} 2$ (4 $\times 5 \mathrm{~m}$ ), com área útil de cada parcela de 4,8 m2 (2,4 x 2 m). A emergência ocorreu entre os dias 26 e 29 de novembro de 2008. A adubação de cobertura foi realizada aos 17 dias após a emergência (DAE), quando as plantas estavam no estádio vegetativo V3/V4, utilizando-se para isso $230 \mathrm{~kg}$ ha-1 de ureia.

Foram realizadas avaliações de 3 características em 4 plantas da fileira central de cada parcela durante o período vegetativo, sendo elas: altura de plantas $(\mathrm{m})$, mensurada do nível do solo até a inserção do limbo foliar da última folha; número de folhas por planta tendo como base a última folha expandida e; diâmetro de colmo, mensurado no segundo entrenó $(\mathrm{cm})$.

A colheita foi realizada manualmente no dia 11 de maio, colhendo-se $2 \mathrm{~m}$ das três fileiras centrais da cada parcela, perfazendo 4,8 m2 de área útil $(2,4 \times 2 \mathrm{~m})$. A debulha foi realizada em todas as espigas colhidas, conferindo-se a umidade através de um medidor universal, para então estimar a produtividade (Prod.) em kg ha-1. Para a determinação da massa de 1000 grãos (MMG) foram retiradas e pesadas oito amostras de 100 sementes de cada parcela, todos os resultados foram corrigidos para 13\% umidade. Previamente selecionou-se ao acaso 4 espigas, das quais se determinou os componentes de produção: o diâmetro (DE) e comprimento de espiga (CE); diâmetro de sabugo (DS); número de fileiras por espiga (NFE), número de grãos por fileira (NGF) e produtividade.

Os dados obtidos para cada variável foram submetidos à análise de variância e as médias dos tratamentos foram comparadas entre si pelo teste de Tukey a $5 \%$ de probabilidade de erro com o auxílio dos programas ESTAT. 


\section{RESULTADOS E DISCUSSÃO}

A análise da variância não detectou significância para a interação entre os fatores tratamento de sementes com micronutrientes e inseticidas para nenhuma das variáveis avaliadas no híbrido de milho $\mathrm{CD} 321 \AA$, optando-se com isso, pela análise dos fatores em separado. Igualmente, não houve efeito significativo do fator tratamento de sementes com inseticidas sobre as variáveis altura de planta (AP), diâmetro de colmo (DC) e número de folhas por planta (NFP) avaliadas aos 20, 50 e 80 dias após a emergência (DAE).

O tratamento de sementes com inseticidas não influenciou a altura das plantas (AP) de milho, híbrido $C D 321 \AA$, independentemente do período de avaliação (Tabela 1). Do mesmo modo, a altura de plantas de milho não foi influenciada significativamente pelo tratamento de sementes com micronutrientes (Tabela 2). Todavia, os coeficientes de variação obtidos demonstraram boa precisão experimental, dado que variaram de 4,19 a 13,69\%, o que segundo Pimentel Gomes (2009) exprime alta homogeneidade dos dados e baixa variação ao acaso (Tabelas 1 e 2 ).

Tabela 1. Altura de planta (AP) do híbrido de milho $C D 321^{\circledR}$, aos 20,50 e 80 dias após a emergência (DAE) em função do tratamento de sementes com inseticidas. Ponta Grossa, PR.

\begin{tabular}{llll}
\hline Tratamentos & \multicolumn{3}{c}{ Altura de planta $(\mathrm{m})$} \\
\cline { 2 - 4 } & $20 \mathrm{DAE}$ & $50 \mathrm{DAE}$ & $80 \mathrm{DAE}$ \\
\hline Inseticidas & $0,21 \mathrm{a}^{1}$ & $1,01 \mathrm{a}$ & $2,31 \mathrm{a}$ \\
Testemunha & $0,21 \mathrm{a}$ & $1,03 \mathrm{a}$ & $2,32 \mathrm{a}$ \\
\hline Média & 0,21 & 1,02 & 2,32 \\
CV $(\%)$ & 13,69 & 12,64 & 4,19
\end{tabular}

${ }^{1}$ Médias seguidas de mesma letra na coluna não diferem entre si pelo teste de Tukey ao nível de $5 \%$ de probabilidade.

Avaliando o efeito de doses de $\mathrm{N}$ aplicadas em cobertura sobre os híbridos de milho AG8025 e P30R50, Gruzska et al. (2016) obtiveram para AP os valores médios de 0,52; 1,50 e 2,41 m quando avaliados em V5; V9 e R1 independentemente do híbrido e da dose de $\mathrm{N}$. Variações na AP entre híbridos de milho, quando da determinação na fase reprodutiva, também foram observadas por Subedi; Ma (2005), apresentando média entre 1,87 a 2,32 m, valores estes, inferior e semelhante aos observados para o híbrido CD321® 
aos $80 \mathrm{DAE}$, respectivamente, independentemente do tratamento de sementes com micronutrientes (Tabela 2). As diferenças observadas caracterizam variabilidade genética entre híbridos de milho para essa variável, além das diferenças edafoclimáticas e das prováveis variações na condução experimental.

Tabela 2. Altura de planta (AP) do híbrido de milho $C D 321^{\circledR}$, aos 20,50 e 80 dias após a emergência (DAE) em função do tratamento de sementes com micronutrientes. Ponta Grossa, PR.

\begin{tabular}{|c|c|c|c|}
\hline \multirow[t]{2}{*}{ Tratamentos } & \multicolumn{3}{|c|}{ Altura de planta (m) } \\
\hline & $20 \mathrm{DAE}$ & $50 \mathrm{DAE}$ & $80 \mathrm{DAE}$ \\
\hline Testemunha & $0,19 \quad a$ & $0,95 \quad a$ & $2,26 \quad a$ \\
\hline Molibdênio (Mo) & $0,23 a^{1}$ & $1,08 \mathrm{a}$ & $2,28 \quad a$ \\
\hline Zinco (Zn) & $0,23 \quad a$ & $1,07 \quad a$ & $2,38 \quad a$ \\
\hline Boro (B) & $0,22 \quad a$ & $1,00 \quad a$ & $2,28 \quad a$ \\
\hline $\operatorname{StarG}^{\circledR}(\mathrm{Zn}+\mathrm{Mo})$ & $0,20 \quad a$ & $1,00 \quad a$ & $2,32 \quad a$ \\
\hline Média & 0,21 & 1,02 & 2,30 \\
\hline CV (\%) & 13,69 & 12,64 & 4,19 \\
\hline
\end{tabular}

${ }^{1}$ Médias seguidas de mesma letra na coluna não diferem entre si pelo teste de Tukey ao nível de $5 \%$ de probabilidade.

O tratamento de sementes com inseticidas não influenciou o diâmetro de colmo (DC) de plantas de milho, híbrido $\mathrm{CD} 321 \AA$, independentemente do período de avaliação (Tabela 3). Gruzska et al. (2016) não obtiveram diferença significativa entre os híbridos AG8025 e P30R50 para a variável DC na fase reprodutiva, cujo valor médio foi de $2,50 \mathrm{~cm}$. Dourado Neto et al. (2003), determinaram como valor médio de DC na fase reprodutiva de 3,08 cm para os híbridos AG1051, AG7575 e DKB911 e Tomazela et al. (2006) para o híbrido P30F33 DC de 2,25 cm. O valor médio de 2,93 cm observado para a variável DC foi superior aos valores encontrados por Gruzska et al. (2016) e Tomazela et al. (2006), porém inferior ao obtido por Dourado Neto et al. (2003). Valores inferiores para esta variável também foram obtidos por Fernandes et al. (2005) para os híbridos simples AG9010 e DKB333B, híbrido triplo CO32, híbrido duplo XB8010, variedades BR106 e Sol da Manhã, os quais foram: 1,$89 ; 1,81 ; 1,80 ; 1,90 ; 1,90$ e $1,98 \mathrm{~cm}$, respectivamente. Posto isso, podese inferir que, as diferenças demonstradas entre o presente estudo para a variável DC e os dados da literatura devem-se não somente à variabilidade edafoclimática e ao manejo, mas também à variabilidade genética entre híbridos. 
Tabela 3. Diâmetro de colmo (DC) do híbrido de milho $C D 321^{\circledR}$, aos 20,50 e 80 dias após a emergência (DAE) em função do tratamento de sementes com inseticida. Ponta Grossa, PR.

Tratamentos

Diâmetro de colmo $(\mathrm{cm})$

\begin{tabular}{llll} 
& $20 \mathrm{DAE}$ & $50 \mathrm{DAE}$ & $80 \mathrm{DAE}$ \\
\hline Inseticidas & $1,32 \mathrm{a}^{1}$ & $3,34 \mathrm{a}$ & $2,97 \mathrm{a}$ \\
Testemunha & $1,36 \mathrm{a}$ & $3,29 \mathrm{a}$ & $2,88 \mathrm{a}$ \\
\hline Média & 1,34 & 3,31 & 2,93 \\
CV $(\%)$ & 16,48 & 9,40 & 10,98
\end{tabular}

${ }^{1}$ Médias seguidas de mesma letra na coluna não diferem entre si pelo teste de Tukey ao nível de $5 \%$ de probabilidade.

O DC de milho não foi influenciado significativamente pelo tratamento de sementes com micronutrientes em nenhuma das avaliações (Tabela 4). Analisando as Tabelas 3 e 4, pode-se observar que houve redução nos valores de DC quando da avaliação aos 80 DAE em relação à realizada aos 50 DAE, redução esta de 11,48\%, independentemente do produto utilizado via tratamento de sementes (inseticida ou micronutriente). O fato possivelmente deriva da redução do teor de água dos colmos mais velhos, bem como da remobilização das reserva neles contidos, uma vez que, a planta de milho aos 80 DAE encontrava-se na fase reprodutiva, fase na qual, o forte dreno passa a ser a estrutura reprodutiva.

Tabela 4. Diâmetro de colmo (DC) do híbrido de milho CD $321^{\circledR}$ aos 20, 50 e 80 dias após a emergência (DAE) em função do tratamento de sementes com bioestimulante. Ponta Grossa, PR.

\begin{tabular}{lllll}
\hline \multirow{2}{*}{ Tratamentos } & \multicolumn{3}{c}{ Diâmetro de colmo $(\mathrm{cm})$} \\
\cline { 2 - 5 } & $20 \mathrm{DAE}$ & $50 \mathrm{DAE}$ & $80 \mathrm{DAE}$ \\
\hline Testemunha & $1,24 \mathrm{a}$ & $3,12 \mathrm{a}$ & $2,67 \mathrm{a}$ \\
Molibdênio (Mo) & $1,43 \mathrm{a}^{1}$ & $3,49 \mathrm{a}$ & $3,03 \mathrm{a}$ \\
Zinco (Zn) & $1,42 \mathrm{a}$ & $3,51 \mathrm{a}$ & $3,14 \mathrm{a}$ \\
Boro (B) & $1,33 \mathrm{a}$ & $3,34 \mathrm{a}$ & $2,99 \mathrm{a}$ \\
StarG & $(\mathrm{Zn}+\mathrm{Mo})$ & $3,09 \mathrm{a}$ & $2,79 \mathrm{a}$ \\
Média & $1,26 \mathrm{a}$ & 3,31 & 2,93 \\
CV (\%) & 1,34 & 9,40 & 10,98
\end{tabular}

${ }^{1}$ Médias seguidas de mesma letra na coluna não diferem entre si pelo teste de Tukey ao nível de $5 \%$ de probabilidade. 
O tratamento de sementes com inseticidas não influenciou o número de folhas por planta (NFP) de milho, híbrido CD321®, independentemente do período de avaliação (Tabela 5). Subedi; Ma (2005) analisando os híbridos de milho Pioneer 3905; Pioneer 39 F06 Bt e Maizex LF 850 RR, obtiveram NFP médios de 16; 16 e 20 respectivamente. Sangoi et al. (2007) obtiveram para o híbrido simples DKB909 em três anos de avaliação 20,7; 19,2 e 19,1 NFP na fase reprodutiva. Nesta mesma fase, Gruzska et al. (2016) lograram NFP médios para os híbridos P30R50 e AG8025 respectivamente de 19,25 e 18,50. O valor médio do NFP aos 80 DAE logrado para o híbrido CD321® foi de 14,02 (Tabela 5), valor este inferior aos dados apresentados na literatura.

Tabela 5. Número de folhas por planta aos 20, 50 e 80 dias após a emergência (DAE) da cultura do milho, híbrido $\mathrm{CD} 321^{\circledR}$, em função do tratamento de sementes com inseticida. Ponta Grossa, PR.

\begin{tabular}{llcc} 
Tratamentos & \multicolumn{3}{c}{ Número de folhas por planta } \\
\cline { 2 - 4 } & $20 \mathrm{DAE}$ & $50 \mathrm{DAE}$ & $80 \mathrm{DAE}$ \\
\hline Inseticidas & $6,14 \mathrm{a}^{1}$ & $13,16 \mathrm{a}$ & $14,35 \mathrm{a}$ \\
Testemunha & $6,21 \mathrm{a}$ & $13,21 \mathrm{a}$ & $13,68 \mathrm{a}$ \\
Média & 6,18 & 13,19 & 14,02 \\
CV $(\%)$ & 12,63 & 7,03 & 6,98
\end{tabular}

${ }^{1}$ Médias seguidas de mesma letra na coluna não diferem entre si pelo teste de Tukey ao nível de $5 \%$ de probabilidade.

O NFP de milho não foi significativamente afetado pelo tratamento de sementes com micronutrientes independentemente da época de avaliação (Tabela 6). Por mais que não tenha havido diferença significativa, pode-se observar que o NFP quando do tratamento de sementes com ZnSO4.7H2O na dose de 16,5 g kg-1 de sementes foi acrescido em $10,35 \%, 6,82 \%$ e 8,32\% em relação à testemunha quando das avaliações aos 20; 50 e 80 DAE, respectivamente (Tabela 6). 
Tabela 6. Número de folhas por planta aos 20,50 e 80 dias após a emergência (DAE) da cultura do milho, híbrido $\mathrm{CD} 321^{\circledR}$, em função do tratamento de sementes com micronutrientes. Ponta Grossa, PR.

\begin{tabular}{|c|c|c|c|}
\hline \multirow[t]{2}{*}{ Tratamentos } & \multicolumn{3}{|c|}{ Número de folhas por planta } \\
\hline & $20 \mathrm{DAE}$ & $50 \mathrm{DAE}$ & $80 \mathrm{DAE}$ \\
\hline Testemunha & $5,89 \quad a$ & $12,71 \quad \mathrm{a}$ & $13,33 \mathrm{a}$ \\
\hline Molibdênio (Mo) & $6,47 \quad a^{1}$ & 13,54 a & 14,42 a \\
\hline Zinco (Zn) & 6,57 a & 13,64 a & 14,54 a \\
\hline Boro (B) & $6,03 \quad a$ & 13,13 a & 14,29 a \\
\hline $\operatorname{StarG}^{\circledR}(\mathrm{Zn}+\mathrm{Mo})$ & $5,91 \quad a$ & $12,91 \quad \mathrm{a}$ & $13,51 \quad a$ \\
\hline Média & 6,18 & 13,19 & 14,02 \\
\hline CV (\%) & 12,63 & 7,03 & 6,98 \\
\hline
\end{tabular}

${ }^{1}$ Médias seguidas de mesma letra na coluna não diferem entre si pelo teste de Tukey ao nível de $5 \%$ de probabilidade.

Os resultados da análise da variância não detectaram significância para a interação entre os fatores tratamento de sementes com micronutrientes e inseticidas para nenhuma das variáveis avaliadas após a colheita do híbrido de milho CD321®. O tratamento de sementes com inseticidas não influenciou o diâmetro de espiga (DE), diâmetro de sabugo (DS), comprimento de espiga (CE), número de fileiras de grãos por espiga (NFGE), número de grãos por fileira (NGF) e massa de 1000 grãos (MMG) do milho, híbrido CD321®, entretanto, a produtividade foi influenciada pelo tratamento de sementes com inseticidas (Tabela 7). Os coeficientes de variação (CV) denotaram mais uma vez, alta homogeneidade dos dados, admitindo-se com isso, que a precisão experimental foi boa (PIMENTEL GOMES, 2009), uma vez que, a variação foi de 13,4 a 3,2\%, tendo sido demonstrada a maior variação ao acaso pela variável produtividade (Tabela 7). 
Tabela 7. Diâmetro de espiga (DE), comprimento de espiga (CE), número de fileiras por espiga (NFGE), número de grãos por fileira (NGF), massa de 100 grãos (MCG), massa de espiga (ME) e produtividade (Prod.) do híbrido de milho CD321 ${ }^{\circledR}$, em função do tratamento de sementes com inseticida. Ponta Grossa, PR.

\begin{tabular}{llllllll}
\hline Tratamentos & $\begin{array}{l}\mathrm{DE} \\
(\mathrm{cm})\end{array}$ & $\begin{array}{l}\mathrm{DS} \\
(\mathrm{cm})\end{array}$ & $\begin{array}{l}\mathrm{CE} \\
(\mathrm{cm})\end{array}$ & NFGE & NGF & $\begin{array}{l}\text { MMG } \\
(\mathrm{g})\end{array}$ & $\begin{array}{l}\text { Prod. } \\
\left(\mathrm{t} \mathrm{ha} \mathrm{-}^{-1}\right)\end{array}$ \\
\hline Inseticidas & $5,4 \mathrm{a}$ & $3,3 \mathrm{a}$ & $14,5 \mathrm{a}$ & $16,2 \mathrm{a}$ & $31,5 \mathrm{a}$ & $369,9 \mathrm{a}$ & $8,8 \mathrm{a}$ \\
Testemunha & $5,3 \mathrm{a}$ & $3,2 \mathrm{a}$ & $13,9 \mathrm{a}$ & $16,7 \mathrm{a}$ & $30,1 \mathrm{a}$ & $363,5 \mathrm{a}$ & $7,6 \mathrm{~b}$ \\
\hline Médias & 5,4 & 3,3 & 14,2 & 16,5 & 30,8 & 366,7 & 8,2 \\
CV (\%) & 3,2 & 3,4 & 7,4 & 4,3 & 8,6 & 4,6 & 13,4
\end{tabular}

${ }^{1}$ Médias seguidas de mesma letra na coluna não diferem entre si pelo teste de Tukey ao nível de $5 \%$ de probabilidade.

O Diâmetro de espiga (DE), diâmetro de sabugo (DS), comprimento de espiga (CE), número de fileiras de grãos por espiga (NFGE), número de grãos por fileira (NGF), massa de 1000 grãos (MMG) e a produtividade não foram significativamente afetados pelo tratamento de sementes com micronutrientes (Tabela 8). Para os componentes da produtividade NFGE, MMG e DE, Gruzska et al. (2016) obtiveram para o híbrido P30R50 os valores médios de 15,35; 358,1 g e 5,09 cm e, para o híbrido AG8025, valores médios de 14,69; 392,0 g e $5,15 \mathrm{~cm}$, respectivamente. Os valores médios obtidos para estas variáveis foram de 16,5; 366,7 g e 5,4 cm (Tabela 8), os quais se aproximam mais dos valores logrados pelo híbrido de milho P30R50 (Gruzska et al., 2016).

Tabela 8. Diâmetro de espiga (DE), diâmetro de sabugo (DS), comprimento de espiga (CE), número de fileiras de grãos por espiga (NFGE), número de grãos por fileira (NGF), massa de 1000 grãos (MMG), massa de espiga (ME) e produtividade (Prod.) do híbrido de milho CD32 ${ }^{\circledR}$, em função do tratamento de sementes com bioestimulantes. Ponta Grossa, PR.

\begin{tabular}{|c|c|c|c|c|c|c|c|}
\hline Tratamentos & $\begin{array}{l}\mathrm{DE} \\
(\mathrm{cm})\end{array}$ & $\begin{array}{l}\text { DS } \\
(\mathrm{cm})\end{array}$ & $\begin{array}{l}\text { CE } \\
(\mathrm{cm})\end{array}$ & NFGE & NGF & $\begin{array}{c}\text { MMG } \\
(\mathrm{g})\end{array}$ & $\begin{array}{l}\text { Prod. } \\
\left(\mathrm{t} \mathrm{ha}^{-1}\right)\end{array}$ \\
\hline Testemunha & $5,2 \mathrm{a}$ & $3,2 \mathrm{a}$ & $13,2 a$ & $16,9 a$ & $28,2 a$ & $355,4 \mathrm{a}$ & $8,0 \mathrm{a}$ \\
\hline Molibdênio (Mo) & $5,3 \mathrm{a}$ & $3,2 \mathrm{a}$ & $14,7 \mathrm{a}$ & $16,5 \mathrm{a}$ & $32,1 \mathrm{a}$ & $371,1 \mathrm{a}$ & $8,2 \mathrm{a}$ \\
\hline Zinco (Zn) & $5,4 \mathrm{a}$ & $3,2 \mathrm{a}$ & $14,7 \mathrm{a}$ & $16,4 \mathrm{a}$ & $31,9 a$ & $373,9 \mathrm{a}$ & $8,7 \mathrm{a}$ \\
\hline Boro (B) & $5,4 \mathrm{a}$ & $3,3 \mathrm{a}$ & $14,7 \quad a$ & $16,3 a$ & 32,0 a & 367,1 a & $8,1 \mathrm{a}$ \\
\hline $\operatorname{Star}^{\circledR}(\mathrm{Zn}+\mathrm{Mo})$ & $5,3 \mathrm{a}$ & $3,2 \mathrm{a}$ & $13,8 \mathrm{a}$ & $16,3 \mathrm{a}$ & 29,8 a & $366,0 \mathrm{a}$ & $8,0 \mathrm{a}$ \\
\hline Médias & 5,4 & 3,3 & 14,2 & 16,5 & 30,8 & 366,7 & 8,2 \\
\hline CV (\%) & 3,2 & 3,4 & 7,4 & 4,3 & 8,6 & 4,6 & 13,4 \\
\hline
\end{tabular}

${ }^{1}$ Médias seguidas de mesma letra na coluna não diferem entre si pelo teste de Tukey ao nível de $5 \%$ de probabilidade. 
Multiplicando-se o valor médio de NGF $(30,8)$ pelo valor médio de NFGE $(16,5)$, terse-ia o valor médio estimado em 508,2 grãos por espiga, correspondendo à massa de grãos por espiga estimada em 186,4 g, calculada em função da massa de mil grãos (MMG), cuja média foi de $366,7 \mathrm{~g}$ (Tabela 8). Valores bastante próximos aos resultados logrados por Tomazela et al. (2006) para o híbrido P30F33, uma vez que, o número médio de grãos por espiga foi de 522,8, equivalendo a MMG de 347,0 g. Corroboram também com os encontrados por Sangoi et al. (2007) em três anos de avaliação para o híbrido simples DKB909 (447, 397 e 400 grãos por espiga, correspondendo a MMG média de 333, 324 e $300 \mathrm{~g}$, respectivamente).

Fernandes et al. (2005) obtiveram para os híbridos simples AG9010 e DKB333B, híbrido triplo CO32, híbrido duplo XB8010, variedades BR106 e Sol da Manhã número médio de grãos por espiga (NGE) de 482,9; 506,4; 534,4; 523,3; 459,4 e 466,9, os quais corresponderam a MMG de 275,1; 277,7; 272,7; 285,9; 233,9 e 269,1 g, respectivamente. Os valores de MMG foram todos inferiores ao obtido para o híbrido CD321® (366,7 g), no entanto, os híbridos simples AG9010 e DKB333B foram semelhantes quanto ao NGE calculado (508,2). O trabalho de Gonçalves et al. (2008) revelou NGE de 528,7, MMG de $238,5 \mathrm{~g}$ e produtividade de $5,7 \mathrm{t}$ ha-1, valores este $3,9 \%$ superior, $35,0 \%$ e $30,5 \%$ inferiores aos valores médios observados neste estudo, respectivamente (Tabela 8).

O valor médio obtido para a variável NGF foi de 30,8 (Tabela 8), inferior aos observados por Gruzska et al. (2016), para os híbridos P30R50 e AG8025, os quais foram 36,0 e 38,4, respectivamente e, por Silva et al. (2005), cujo valor foi de 38,6 NGF. As diferenças encontradas se devem provavelmente a variações edafoclimáticas, de manejo, bem como da variabilidade genética.

O CE médio obtido, independentemente do tratamento de sementes com inseticidas e com micronutrientes foi de $14,2 \mathrm{~cm}$ (Tabela 8). Valor este, inferior ao encontrado por Gruzska et al. (2016), o qual foi de 18,0 cm e aos encontrados por Subedi; Ma (2005) para três híbridos de milho (15,9; 16,0 e 16,2 cm), indicando prováveis diferenças genéticas entre híbridos.

A produtividade encontrada por Gruzska et al. (2016) para o híbrido P30R50 foi de 10,93 t ha-1 e para o AG8025 12,44 t ha-1, valores 25,0 e 34,1\% superiores aos obtidos para o híbrido CD321® (Tabela 8). Produtividades superiores também foram demonstradas por Argenta et al. (2003) para os híbridos P32R21 e Premium, as quais foram de 12,4 e 9,5 t ha-1, respectivamente. Diferença entre híbridos de milho quanto à produtividade também foi observada por Ferreira et al. (2009), tendo sido os híbridos AG9020 e AG8021 mais 
produtivos que o AG6018, no entanto, a produtividade máxima pelos autores encontrada foi de 10,6 t ha-1, maior em 2,4 t ha-1 ao valor médio obtido neste trabalho (Tabela 8).

Dentre os micronutrientes utilizados no tratamento de sementes neste estudo, 0 que a literatura indica como o com maior probabilidade de efeito, independentemente da cultura, é o zinco (OHSE et al., 1997; OHSE et al., 1999; OHSE et al., 2000; OHSE et al., 2013; PRADO et al., 2007; PLETSCH et al., 2014). A deficiência de Zn é reconhecida como problema nutricional mundial para a produção das culturas, particularmente, para as poáceas que são exigentes neste micronutriente (FAGERIA, 2000).

O Zn apresenta inúmeras funções na planta, como por exemplo, sua participação nas enzimas superóxido dismutase (SD) e catalase, as quais evitam efeitos deletérios das espécies reativas de oxigênio (EROs) e, sua exigência para a síntese do aminoácido triptofano, precursor do ácido indolacético (AIA), principal auxina produzidas pelas plantas e, fitormônio que apresenta maior número de efeitos conhecidos, tais como; alongamento e diferenciação celular, divisão celular, foto e geotropismo, formação de raízes, regeneração dos tecidos vasculares entre outros (TAIZ et al., 2017). Em plantas de milho deficientes em $\mathrm{Zn}$, comumente se observa decréscimo do tamanho das plantas, devido à redução do comprimento dos internódios (FURLANI et al., 2005), o que se deve a participação do Zn na síntese de auxina.

O fato de não ter havido efeito significativo do tratamento de sementes com $\mathrm{Zn}$ sobre as variáveis AP, DC, NFP, DE, DS, CE, NFGE, NGF, MMG e PROD., pode ser justificado pelo fato do teor de $\mathrm{Zn}(2,9 \mathrm{mg} \mathrm{dm}-3)$ presente no solo ter sido suficiente para suprir as necessidades da cultura, dado que, segundo Fancelli; Dourado Neto (2004), a quantidade necessária de Zn no solo para a cultura do milho encontra-se entre 0,5 e 1,0 mg dm-3 (DTPA). Galrão (1996), considera como nível crítico para um Latossolo VermelhoEscuro o teor de 0,6 mg dm-3 (DTPA). Dessa forma, o teor de $\mathrm{Zn}$ no solo da área experimental pode ter sido suficiente para suprir a demanda da cultura não ocasionando resposta à aplicação de $\mathrm{Zn}$ via tratamento de sementes para as variáveis avaliadas.

A temperatura média durante o período experimental variou de 15,1 a $21,40 \mathrm{C}$ o que, provavelmente, fez com que a cultura do milho, híbrido CD321®, não expressasse seu potencial produtivo. Fato ligado, sem sombra de dúvidas, ao milho ser uma planta C4, a qual tem como temperatura ótima aproximadamente $30 \mathrm{oC}$. Além disso, é uma planta que não satura em função da intensidade luminosa e a RUBISCO (ribulose 1,5 bifosfato carboxilase/oxigenase), enzima mais populosa do planeta, responsável pela fixação e redução do carbono, único processo na natureza que une átomos de carbono entre si, 
gerando a fitomassa seca (esqueletos carbônicos), fazendo com que o organismo, no caso o milho, possa crescer e se desenvolver, é ativada pela luz. A produtividade não foi influenciada pelo tratamento de sementes com inseticidas e nem pelos produtos micronutrientes, diferentemente de Bertolin et al. (2010) e corroborando com Ferreira et al. (2007). Contudo, a média obtida (8,2 t ha-1) foi superior à média nacional da primeira safra 2017/18, a qual foi de 5,3 tha-1 (CONAB, 2018).

A cultura do milho, híbrido CD321®, esteve submetida a estresse hídrico mediano durante 44 DAE, período no qual o potencial produtivo da cultura é definido. A deficiência hídrica gera efeitos em cascata, por ser a água o veículo pelo qual os nutrientes são solubilizados, absorvidos e translocados, além de ser o meio no qual todo e qualquer processo fisiológico ocorre. Este fato pode ter influenciados os resultados obtidos, visto que os produtos, inseticidas e micronutrientes, foram aplicados via sementes e, sua absorção e utilização ocorrem durante a germinação e fase inicial do desenvolvimento autotrófico. Quando do início da fase autotrófica, a deficiência hídrica induz a planta a ampliar o período em que mantém os estômatos fechados, minimizando a transpiração, porém reduzindo a fotossíntese líquida e, consequentemente, o desenvolvimento e a produtividade das culturas. Entretanto, o fato da média obtida (8,2 t ha-1) ter sido superior $35,4 \%$ superior à média nacional da primeira safra 2017/18 (5,3 t ha-1) (CONAB, 2018) se deve, provavelmente ao fato do milho ser uma planta $\mathrm{C} 4$, o que a torna mais eficiente no uso da água que uma planta C3. Embora a produtividade tenha sido maior que a nacional, foi 6,3\% inferior à média do Paraná (8,75 t ha-1), encontrando-se muito aquém do potencial produtivo da cultura, o qual é superior a 16 t ha-1, segundo Coelho et al. 2003.

\section{CONCLUSÕES}

O tratamento de sementes com o inseticida Cropstar® [imidacloprido+tiodicarbe] na dose $4 \mathrm{~mL} \mathrm{kg-1} \mathrm{de} \mathrm{sementes,} \mathrm{mesmo} \mathrm{tendo} \mathrm{reduzido} \mathrm{o} \mathrm{número} \mathrm{de} \mathrm{fileiras} \mathrm{por} \mathrm{espiga,}$ influenciou positivamente a produtividade da cultura do milho, híbrido CD321®, proporcionando aumento de $13,6 \%$.

O tratamento de sementes com micronutrientes ( $\mathrm{Zn}, \mathrm{B}$, Mo e $\mathrm{Zn+Mo}$ [StarG®]) não influenciou o desenvolvimento e o potencial produtivo da cultura do milho, híbrido CD321®. 


\section{REFERÊNCIAS}

ALBUQUERQUE, F.A. de; BORGES, L.M.; IACONO, T. de O.; CRUBELATI3, N.C. de S.; SINGER,A. de C. Eficiência de inseticidas aplicados em tratamento de sementes e em pulverização, no controle de pragas iniciais do milho. Revista Brasileira de Milho e Sorgo, v.5, n.1, p.15-25, 2006.

ARGENTA, G.; SILVA, P. R. F.; FOSTHOFER, E. L.; STRIEDER, M. L.; SUHRE, E.; TEICHMANN,L. L. Adubação nitrogenada em milho pelo monitoramento do nível de nitrogênio na planta por meio do clorofilômetro. Revista Brasileira de Ciência do Solo, v. 27, p. 109-119, 2003.

ÁVILA, M.R.; BRACCINI, A. de L. e; SCAPIN, C.A.; MARTORELLI, D.T.; ALBRECHT, L.P.; FACIOLLI, F.S. Qualidade fisiológica e produtividade das sementes de milho tratadas com micronutrientes e cultivadas no período de safrinha. Revista Acta Scientiarum Agronomy, v. 28 , n. 4 , p. 535-543, 2006.

ÁVILA, M.R.; BRACCINI, A.L.; SCAPIM, C.A.; ALBRECHT, L.P.; TONIN, T.A.; STÜLP, M. Bioregulador application, agronomic efficiency, and quality of soybean seeds. Scientia Agricola, v.65, n.6, p.567-691, 2008.

BERTOLIN, D.C.; EUSTÁQUIO de SÁ, M.; ARF, O.; FURLANI JUNIOR, E.; COLOMBO, A. de S.; MELO de CARVALHO, F.L.B. Aumento da produtividade de soja com a aplicação de bioestimulantes. Bragantia, v.69, n.2, p.339-347, 2010.

COELHO, A.M.; CRUZ, J.C.; PEREIRA FILHO, I.A. Rendimento do milho no Brasil: chegamos ao máximo? Piracicaba:POTAFOS, Informações Agronômicas, 101, p.1-12, 2003.

CONAB-COMPANHIA NACIONAL DE ABASTECIMENTO. Acompanhamento de safra brasileira: grãos. Brasília, DF: Conab, 2018. $12^{\circ}$ Levantamento - Safra 2017/2018. Disponível em: www.conab.gov.br/info-agro/safras/graos/boletim-da-safra-de-graos. Acesso em: 18 de setembro de 2018. 
DOURADO NETO, D.; DARIO, G.J.A.; VIEIRA JÚNIOR, P.A.; MANFRON, P.A.; MARTIN, T.N.; BONNECARRÉRE, R.A.G.; CRESPO, P.E.N. Aplicação e influência do fitorregulador no crescimento das plantas de milho. Revista da Faculdade de Zootecnia, Veterinária $e$ Agronomia,v.11, n.1, p.1-9, 2004.

DOURAdo NeTO, D.; PAlHARES, M.; VIEIRA, P. A.; MANFRON, P. A.; MEdEIROS, S. L. P.; ROMANO, M. R. Efeito da população de plantas e do espaçamento sobre a produtividade de milho. Revista Brasileira de Milho e Sorgo, v. 2, n. 3, p. 63-77, 2003.

EMBRAPA-Empresa Brasileira de Pesquisa Agropecuária. Sistema Brasileiro de Classificação de Solos. 2.ed. Rio de Janeiro: Embrapa Solos, 2006. 306p.

FAGERIA, N.K. Níveis adequados e tóxicos de zinco na produção de arroz, feijão, milho, soja e trigo em solo de cerrado. Revista Brasileira de Engenharia Agrícola e Ambiental, v.4, n.3, p.390-395, 2000.

FANCELLI, A.L.; DOURADO NETO, D. Produção de milho. [S/L]:Livraria e Editora Livroceres, 2004. 360p.

FERNANDES, F.C.S.; BUZETTI, S.; ARF, O.; ANDRADE, J.A. da C. Doses, eficiência e uso de nitrogênio por seis cultivares de milho. Revista Brasileira de Milho e Sorgo, v. 4, n. 2, p. 195-204, 2005.

FERREIRA, A. de O; SA, J.C. de M.; BRIEDIS, C.; FIGUEIREDO, A.G. de. Desempenho de genótipos de milho cultivados com diferentes quantidades de palha de aveia-preta e doses de nitrogênio. Pesquisa Agropecuária Brasileira, v. 44, n. 2, p. 173-179, 2009.

FERREIRA, L.A.; OLIVEIRA, J.A.; VON PINHO, É.V. de R.; QUEIROZ, D.L. de. Bioestimulante e fertilizante associados ao tratamento de sementes de milho. Revista Brasileira de Sementes, v.29, n.2, p-80-89, 2007.

FURLANI, A.C.G.; FURLANI, P.R.; MEDA, A.R.; DUARTE, A.P. Efficiency of maize cultivars for zinc uptake and use. Scientia Agricola, v.62, n.3, p.264-273, 2005. 
GALLO, D. (Ed.). Entomologia Agrícola. Piracicaba: FEALQ, 2002. 920p.

GONÇALVES, A.C. Jr.; NACKE, H.; STREY, L.; SCHWANTES, D.; SELZLEIN, C. Produtividade e componentes de produção do milho adubado com $\mathrm{Cu}$ e NPK em um ARGISSOLO. Revista Scientia Agraria, v. 9, n. 1, p. 35-40, 2008.

GRUZSKA, M.; OHSE, S.; PEREIRA, A.B.; SANTOS DIAS, C.T. dos. Corn yield as a function of amounts of nitrogen applied in bands. African Journal Agricultural Research, v.11, n.20, p.1805-1814. 2016.

KLAHOLD, C.A.; GUIMARÃES, V.F.; ECHER, M.M.; KLAHOLD, A.; CONTIERO, R.L.; BECKER, A. Resposta da soja (Glycine max (L.) Merrill) à ação de bioestimulante. Acta Scientiarum Agronomy, v.28, n.2, p.179-185, 2006.

MARCHEZAN, E.;SANTOS, O.S. dos; AVILA, L.A. de; SILVA, R.P. da. Adubação foliar com micronutrientes em arroz irrigado, em área sistematizada. Ciência Rural, v.31, n.6, p.941-945, 2001.

OHSE, S.; MARODIM, V.S.; SANTOS, O.S.; LOPES, S.J.; MANFRON, P.A. Germinação e vigor de sementes de arroz irrigado tratadas com zinco, boro e cobre. Revista da Faculdade de Zootecnia, Veterinária e Agronomia, v.7, n.1, p.75-81, 2000.

OHSE, S.; SANTOS, L.L.P. dos; CORTEZ, M.G.; GODOY, A.R.; OTTO, R.F. Tratamento de sementes de milho branco crioulo com micronutrientes. Visão Acadêmica, v.14, n.4, p.26-35, 2013.

OHSE, S.; SANTOS, O.S.; MARODIM, V.S.; MANFRON, P.A. Efeito do tratamento de sementes de arroz irrigado com zinco em relação à aplicação no substrato. Revista da Faculdade de Zootecnia, Veterinária e Agronomia, v.5/6, n.1, p.35-41, 1999.

OHSE, S.; SANTOS, O.S.; MENEZES, N.L.; SCHMIDT, D. Efeito de fontes e doses de zinco sobre a germinação e o vigor de sementes de arroz irrigado. Revista Brasileira de Sementes, v.19, n.2, p.370-374, 1997.

PEEL, M.C.; FINLAYSON, B.L.; MCMAHON, T.A. Updated world map of the Köppen-Geiger 
climate classification. Hydrology and Earth System Sciences Discussions, v.11, p.16331644, 2007.

PIMENTEL GOMES, F.P. Curso de Estatística Experimental. 15ํㅡㄹ. Ed., Livraria Nobel S.A., São Paulo. 2009. 451p.

PLETSCH, A.; SILVA, V.N.; BEUTLER, A.N. Tratamento de sementes de canola com zinco. Revista de Ciências Agrárias, v.37, n.2, p.241-247. 2014.

PRADO, R. de M.; NATALE, W; MOURO, M. de C. Fontes de zinco aplicado via semente na nutrição e crescimento inicial do milho cv. Fort. Bioscience Journal, v.23, n.2, p.16-24, 2007.

QUINTELA, E.D.; SILVA, J.F.A.;FERREIRA, S.B.; OLIVEIRA, L.F.C. de; LEMES, A.C. de O. CropStar - Efeito do tratamento de sementes com inseticidas químicos sobre danos de percevejos fitófagos e sobre a lagarta do cartucho no milho. Circular 76, 2006. 6p.

RIBEIRO, N.D.; SANTOS, O.S. dos. Aproveitamento do zinco aplicado na semente na nutrição da planta. Ciência Rural, v.26, n.1, p.159-165, 1996.

RIBEIRO, N.D.; SANTOS, O.S. dos. Germinação de sementes de milho tratadas com fontes e doses de zinco e boro. Ciência Rural, v.21, n.3, p.437-440, 1991.

SANGOI, L.; ERNANI, P.R.; SILVA, P.R.F. da. Maize response to nitrogen fertilization timing in two tillage systems in a soil with high organic matter content. Revista Brasileira de Ciência do Solo, v. 31, p. 507-517, 2007.

SANTOS, O.S. dos; RIBEIRO, N.D. Fontes de zinco aplicadas em sementes de milho, em solução nutritiva. Ciência Rural, v.24, p.59-62, 1994.

SANTOS, O.S.; ESTEFANEL, V. Efeito de micronutrientes e do enxofre aplicados nas sementes de soja. Ciência Rural, v.16, n.1, p.5-17, 1986.

SILVA, E. C. da; BUZETTI, S.; GUIMARÃES, G. L.; LAZARINI, E.; SÁ, M. E. de. Doses e 
épocas de aplicação de nitrogênio na cultura do milho em plantio direto sobre latossolo vermelho. Revista Brasileira de Ciência do Solo, v. 29, n. 3, p.353-362, 2005.

SILVA, E.S. Produção de grãos de milho em função de níveis de adubação com zinco e boro aplicados nas sementes e no solo. Rio Verde, Goiás, 1989. 43 p. Dissertação (Graduação em Agronomia) - Curso de Graduação em Engenharia Agronômica, Escola Superior de Ciências Agrárias, 1989.

SUBEDI, K.D.; MA, B.L. Nitrogen uptake and partitioning in stay-green and leafy maize hybrids. Crop Science, v. 45, p. 740-747, 2005.

TAIZ, L.; ZEIGER, E.; MOLLER, I.M.; MURPHY, A. Fisiologia e desenvolvimento vegetal. 6a.ed. Porto Alegre: Artmed, 2017.

TOMAZELA, A. L.; FAVARIN, J. L.; FANCELLI, A. L.; MARTIN, T. N.; DOURADO NETO, D.; REIS, A. R. dos. Doses de nitrogênio e fontes de $\mathrm{Cu}$ e $\mathrm{Mn}$ suplementar sobre a severidade da ferrugem e atributos morfológicos do milho. Revista Brasileira de Milho e Sorgo, v. 5, n. 2, p. 192-201, 2006.

USDA - UNITED STATES DEPARTMENT OF AGRICULTURE. Foreign Agricultural Service (FAS). Grain: world mar-kets and trade. United States: USDA/FAS, nov. 2017. Disponível em: <https://apps.fas.usda.gov/psdon-line/circulars/grain.pdf>. Acesso em: nov. 2018. 